\title{
Amphetamine Effects on Prepulse Inhibition Across-Species: Replication and Parametric Extension
}

\author{
Neal R Swerdlow*,', Nora Stephany', Lindsay C Wasserman', Jo Talledo', Jody Shoemaker' and Pamela P \\ Auerbach' \\ 'Department of Psychiatry, UCSD School of Medicine, La Jolla, CA, USA
}

\begin{abstract}
Despite the similarities of prepulse inhibition (PPI) of the startle reflex and its apparent neural regulation in rodents and humans, it has been difficult to demonstrate cross-species homology in the sensitivity of PPI to pharmacologic challenges. PPI is disrupted in rats by the indirect dopamine (DA) agonist amphetamine, and while studies in humans have suggested similar effects of amphetamine, these effects have been limited to populations characterized by smoking status and specific personality features. In the context of a study assessing the time course of several DA agonist effects on physiological variables, we failed to detect PPI-disruptive effects of amphetamine in a small group of normal males. The present study was designed to reexamine this issue, using a larger sample and a paradigm that should be more sensitive for detecting drug effects. PPI in rats was shown to be disrupted by the highest dose of amphetamine (3.0 mg/ $\mathrm{kg})$ at relatively longer prepulse intervals $(>30 \mathrm{~ms})$. In humans, between-subject comparisons of placebo $(n=15) \mathrm{vs} 20 \mathrm{mg}$ amphetamine $(n=15)$ failed to detect significant PPI-disruptive effects of amphetamine, but significant PPI-disruptive effects at short (I0-20 ms) prepulse intervals were detected using within-subject analyses of postdrug PPI levels relative to each subject's baseline PPI. Post hoc comparisons failed to detect greater sensitivity to amphetamine among subjects characterized by different personality and physiological traits. Bioactivity of amphetamine was verified by autonomic and subjective changes. These results provide modest support for crossspecies homology in the PPI-disruptive effects of amphetamine, but suggest that these effects in humans at the present dose are subtle and may be best detected using within-subject designs and specific stimulus characteristics.
\end{abstract}

Neuropsychopharmacology (2003) 28, 640-650. doi:I 0.I 038/sj.npp. 1300086

Keywords: amphetamine; prepulse inhibition; personality; schizophrenia; startle

\section{INTRODUCTION}

Deficits in prepulse inhibition (PPI) of acoustic startle have been identified in several neuropsychiatric disorders, including schizophrenia and Tourette syndrome, and the neurobiology of PPI deficits has been the focus of intense study in humans and animal models. One of the challenges in these studies is to determine the degree to which the neural substrates regulating PPI and PPI deficits can be translated across species, from rodents to humans. To date, findings related to the neural regulation of PPI in humans and rats suggest both similarities and differences across species.

For example, there is evidence for cross-species homology in the regulation of PPI by certain components of corticostriato-pallido-thalamic (CSPT) circuitry. PPI is impaired both in patients with Huntington's disease (HD) (Swerdlow et al, 1995), and in mice (Carter et al, 1999) and rats (Kodsi

*Correspondence: Dr NR Swerdlow, Department of Psychiatry, UCSD School of Medicine, La Jolla, CA 92093-0804, USA, Fax: +1 619543 2493, E-mail: nswerdlow@ucsd.edu

Received 8 April 2002; revised 3 July 2002; accepted 30 August 2002 Online publication: 13 September 2002 at http://www.acnp.org/ citations/Npp09/302379 and Swerdlow, 1997) with genetically or surgically induced damage of the striatum. Other studies suggest that diminished prepulse effects on startle in schizophrenia are associated with a failure to activate midline thalamic nuclei (Hazlett et al, 1998), and transient chemical inactivation of this region in the rat is accompanied by PPI deficits (Swerdlow et al, 2002c). Some neuropharmacologic homology is suggested by the disruption of PPI in humans and rats by indirect (Hutchison and Swift, 1999; Hutchison et al, 1999) and direct (Abduljawad et al, 1997, 1998) dopamine (DA) agonists, and the enhancement of PPI in humans and rats by nicotine (Kumari et al, 1996; Curzon et al, 1994).

However, the cross-species differences in PPI neuropharmacology are equally striking. The noncompetitive NMDA antagonist ketamine enhances prepulse facilitation elicited by short prepulse intervals $(30 \mathrm{~ms})$, and reduces or eliminates PPI elicited with longer prepulse intervals (30$500 \mathrm{~ms}$ ) in rats (Mansbach and Geyer, 1989). In humans, however, studies using $30-120 \mathrm{~ms}$ prepulse intervals have identified only PPI-potentiating effects of ketamine (van Berckel et al, 1998; Duncan et al, 2001). The indirect DA agonist/uncompetitive NMDA antagonist amantadine exhibits a biphasic interval-dependent effect on PPI in rats (potentiation at short intervals, disruption at long inter- 
vals), and in humans we have observed only significant PPIpotentiating effects of this drug across a range of intervals (Swerdlow et al, 1998, 2001a).

The cross-species complexities are not limited to the NMDA regulation of PPI. For example, the substituted amphetamine 3,4-methylenedioxy-methamphetamine (MDMA) reduces PPI in rats (Mansbach et al, 1989) and increases PPI in humans (Vollenweider et al, 1999). A careful assessment of the effects of dopaminergic drugs on human PPI reveals that the indirect DA agonist amphetamine reduced PPI only in specific subgroups of humans, distinguished by their smoking history (Kumari et al, 1998) or personality features (Hutchison et al, 1999). That different subsets of humans might be more or less sensitive to these PPI-disruptive effects is not surprising, given the ample preclinical evidence for infrahuman strain differences in sensitivity to the PPI-disruptive effects of DA agonists (Swerdlow et al, 2000b, 2001c). One report of reduced PPI in humans treated with the D2 blocker haloperidol (Abduljawad et al, 1998) is also at odds with the predominant effect of haloperidol on PPI in rats (Mansbach et al, 1988; Swerdlow et al, 1994; cf Swerdlow and Geyer, 1998; cf Geyer et al, 2001), although we have also occasionally observed PPI-reducing effects of this drug in rats, particularly juveniles (Martinez et al, 2002). Finally, our findings have led us to question the robustness of the PPI-disruptive effects of the D2 agonist bromocriptine in humans, but this may not be surprising, since this bromocriptine effect in rats is also relatively weak, and observed only with high doses and relatively long $(\geqslant 60 \mathrm{~ms})$ prepulse intervals (Swerdlow et al, 1998, 2002f).

While there are considerable challenges to translating the neural substrates regulating PPI from rat to man, this process may pay substantial dividends. PPI deficits are being used successfully in a number of important lines of investigation, from the development of novel antipsychotic agents (Swerdlow et al, 1994; Mansbach et al, 1998; cf Swerdlow and Geyer, 1998; cf Geyer et al, 2001) to the identification of vulnerability genes for schizophrenia (Joober et al, 2002; cf Braff and Freedman, 2002). These efforts would benefit greatly from a map of the neural circuit regulation of PPI in humans, which could guide the search for functional targets of therapeutic drugs and candidate genes.

The present study was designed to extend our understanding of the dopaminergic regulation of PPI across species by testing three specific hypotheses. In a study surveying the time courses of four different DA agonists' effects on psychological and psychophysiological measures, we failed to detect any evidence of amphetamine-induced PPI deficits in a small group of subjects (active dose (20 mg): $n=6)$ using a simplified test session with only a single-prepulse interval (100 ms) (Swerdlow et al, 2002b). One aim of the present study was to extend this assessment, using a larger sample and a range of short-to-long prepulse intervals (10-120 ms). Previous studies have demonstrated both dose- and interval-dependent effects of DA agonists on PPI in rats using this range of prepulse intervals (MartinIverson and Else, 2000; Swerdlow et al, 2001d, 2002f), and the present study tested the hypothesis that there are interval-dependent effects of amphetamine on PPI across this interval range in rats and humans; conceivably, we may have missed such effects of amphetamine on PPI in normal humans by using only the $100 \mathrm{~ms}$ prepulse interval in our previous work (Swerdlow et al, 2002b). Findings from other groups have suggested that certain population characteristics might make individuals more 'sensitive' to the effects of amphetamine, and particularly its PPI-disruptive effects (Kumari et al, 1998; Hutchison et al, 1999). For this reason, we tested the hypothesis that amphetamine-induced PPI deficits might be detected in specific subsets of normal human subjects, characterized by personality and physiological markers associated with amphetamine sensitivity ('Sensation Seeking' (Zuckerman et al, 1972)) and brain DA function ('Novelty Seeking' (Cloninger et al, 1991) and spontaneous blink rate (Karson et al, 1980, 1984)). Finally, sensorimotor gating measured by PPI is related conceptually and perhaps neurobiologically to other measures of stimulus 'gating', and it is conceivable that these related measures may be sensitive to 'gating-disruptive' effects of amphetamine. For example, 'sensory' gating - as assessed by PPI of perceived stimulus intensity (PPIPSI; Swerdlow et al, 1999) - is disrupted in humans by the indirect DA agonist amantadine (Swerdlow et al, 2001a, 2002f), and tactile startle habituation, like PPI, is impaired in schizophrenia patients (Geyer and Braff, 1982). In the present study, we tested the hypothesis that amphetamine would disrupt sensory gating - measured by PPIPSI - and startle reflex habituation in normal human subjects.

\section{METHODS}

\section{Rat Studies}

A total of 34 male Sprague-Dawley rats (225-250 g; Harlan Laboratories) were housed in groups of 2-3 and maintained on a reversed 12:12 h light/dark schedule (lights off at 0700), with food and water provided ad libitum. Behavioral testing occurred between 0900 and 1700. Animals were handled individually within 3 days of arrival, and 2-3 $\times 1$ week thereafter.

Each of four startle chambers (SR-LAB, San Diego Instruments, San Diego, CA) was housed in a soundattenuated room with a $60 \mathrm{~dB}(\mathrm{~A})$ ambient noise level, and consisted of a Plexiglas cylinder $8.2 \mathrm{~cm}$ in diameter resting on a $12.5 \times 25.5 \mathrm{~cm}^{2}$ Plexiglas frame within a ventilated enclosure. Acoustic noise bursts were presented via a speaker mounted $24 \mathrm{~cm}$ above the animal. A piezoelectric accelerometer mounted below the Plexiglas frame detected and transduced motion within the cylinder. The delivery of acoustic stimuli was controlled by the SR-LAB microcomputer and interface assembly, which also rectified, digitized (0-4095), and recorded stabilimeter readings, with 100 one$\mathrm{ms}$ readings collected beginning at stimulus onset. Startle amplitude was defined as the average of the 100 readings. Background noise and all acoustic stimuli were delivered through one Radio Shack Supertweeter (frequency response predominantly between 5 and $16 \mathrm{kHZ}$ ) in each chamber. Stimulus intensities and response sensitivities were calibrated to be nearly identical in each of the four startle chambers (maximum variability $<1 \%$ of stimulus range and $<5 \%$ of response ranges). Chambers were also balanced across all experimental groups. Sound levels were measured and calibrated with a Quest Sound Level Meter, A 
Table I Subject Characteristics

\begin{tabular}{|c|c|c|c|c|c|c|c|c|c|}
\hline Drug group & $\begin{array}{l}\text { Age (years) } \\
\text { mean (SD) }\end{array}$ & $\begin{array}{c}\text { Mean drug } \\
\text { dose }(\mathrm{mg} / \mathrm{kg})\end{array}$ & $\begin{array}{l}\text { Ethnicity } \\
(C: A: H)^{a}\end{array}$ & $\begin{array}{l}\text { Daily caffeine } \\
\text { (mg) mean } \\
\text { (SEM) }\end{array}$ & $\begin{array}{c}\text { Blinks/3min } \\
\text { mean } \\
\text { (SEM) }\end{array}$ & $\begin{array}{l}\text { SSS total } \\
\text { score mean } \\
\text { (SEM) }\end{array}$ & \multicolumn{3}{|c|}{ TPQ subscale score (mean (SEM)) } \\
\hline $\begin{array}{l}\text { Placebo } \\
n=15\end{array}$ & $22.33(1.30)$ & $N / A$ & $9: 4: 2$ & $91.62(39.12)$ & $58.93(11.70)$ & $24.36(1.11)$ & $20.33(1.22)$ & $7.53(1.56)$ & $21.07(0.95)$ \\
\hline
\end{tabular}

${ }^{\mathrm{a}}$ Caucasian: Asian: Hispanic.

scale (relative to $20 \mu \mathrm{N} / \mathrm{m}^{2}$ ), with the microphone placed inside the Plexiglas cylinder; response sensitivities were calibrated using an SR-LAB Startle Calibration System.

After a $5 \mathrm{~min}$ acclimation period with $70 \mathrm{~dB}(\mathrm{~A})$ background white noise, rats were exposed to 42 trials that included six conditions: a $120 \mathrm{~dB}(\mathrm{~A}) 40 \mathrm{~ms}$ noise burst presented alone (P-ALONE); and the same $120 \mathrm{~dB}(\mathrm{~A}) 40 \mathrm{~ms}$ noise burst preceded $10,20,30,60$, or $120 \mathrm{~ms}$ by a prepulse (5 ms noise burst) that was $15 \mathrm{~dB}(\mathrm{~A})$ above background (PP10, PP20, PP30, PP60, and PP120 ms, respectively). The session began and ended with three consecutive P-ALONE trials; between these trials, the six trial types were each repeated six times in pseudorandom order. Intertrial intervals averaged $15 \mathrm{~s}$ (range 10-20 s). Testing began $10 \mathrm{~min}$ after treatment with amphetamine (vehicle (saline), $0.03,0.3$, and $3.0 \mathrm{mg} / \mathrm{kg}$, s.c., $n=8-10 /$ dose). The highest dose $(3.0 \mathrm{mg} / \mathrm{kg})$ was selected based on dose-response effects on rat PPI detected in previous studies (Mansbach et al, 1988); the lower doses were selected based on our findings that PPI-enhancing effects of DA agonists can be observed at doses that are orders of magnitude lower than those that consistently disrupt PPI (Swerdlow et al, 2001d).

\section{Human Studies}

The methods used in these studies were very similar to those used in studies described in a recent report (Swerdlow et $a l, 2002 \mathrm{a}$ ), were approved by the UCSD Human Subjects Institutional Review Board (IRB 011202), and were approved and supported by the National Institute of Mental Health (MH 59803). A total of $30 \mathrm{R}$ handed males (Table 1) completed testing; the study involved phone contact and two laboratory visits (Figure 1) and subjects were paid $\$ 140$ (US) for study completion. Phone screening procedures were identical to those described in previous reports from our group (Swerdlow et al, 2000a, 2002b).

As in Swerdlow et al (2000a, 2002b), the present human drug studies had a modified between-subject design (Figure 1 ), in which all subjects received a limited startle 'pretest' without drug, followed approximately 1 week later by a more extensive test day that began with consumption of either placebo or active drug. During the 'pretesting' session the Principle Investigator (NRS) informed each subject $(n=48)$ of the potential risks and benefits of the study. Subjects also read and signed a consent for study participation, and completed a urine toxicology test with exclusion for any drug. Subjects completed a startle 'matching test' to assess acoustic startle reflex; six subjects were excluded for mean eyeblink acoustic startle magnitude $<50$ units. EMG methodology was identical to that in

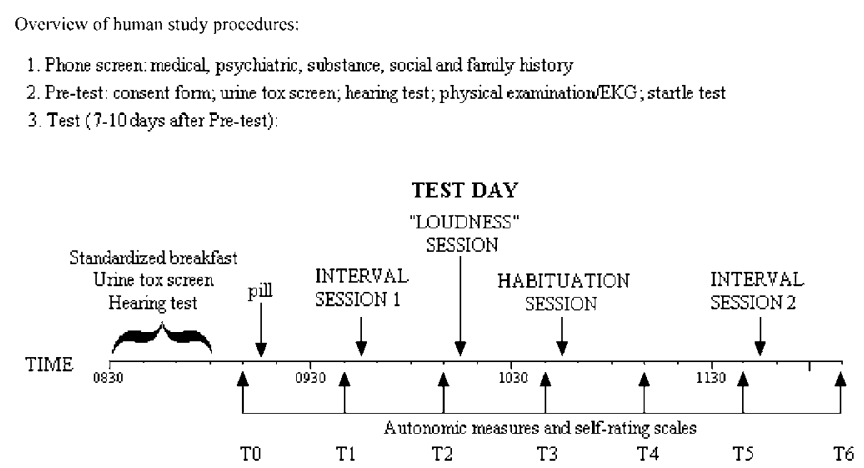

Figure I Overview of human study procedures, including time line of test day.

Swerdlow et al (2000, 2002). Subjects also completed the Tridimensional Personality Questionnaire (TPQ) (Cloninger et al, 1991) to assess the relation between novelty seeking scores (NS) and sensitivity to the effects of amphetamine on PPI, based on reports that high NS individuals are most sensitive to the PPI-disruptive effects of amphetamine (Hutchison et al, 1999). Data from the pretest session in a subset of the present sample were included as part of a large $(n=80)$ report on the relation between personality and eyeblink characteristics on baseline (drug free) PPI (Swerdlow et al, 2002a). Subjects also completed the Sensation Seeking Scale (Zuckerman et al, 1972), based on reported increased sensitivity to amphetamine in individuals scoring high on this measure (Hutchison et al, 1999).

Subjects sat upright during all startle sessions, were directed to look straight ahead, and to stay awake. Acoustic startle stimuli were delivered by Telephonics (TDH-39-P, Maico) headphones. During each startle session, a background $65 \mathrm{~dB}(\mathrm{~A})$ white noise continued throughout the session and was followed $3 \mathrm{~min}$ after onset by the startle trials. During this acclimation period, the number of spontaneous eyeblinks was counted by a remote observer using a Radio Shack security camera system (model 492513) (interobserver $R=0.97$ ). The startle session during pretesting consisted of the 'INTERVAL session'. The INTERVAL session consisted of 42 trials that included six conditions: a $118 \mathrm{~dB}(\mathrm{~A}) 40 \mathrm{~ms}$ noise burst presented alone (P-ALONE); and the same $118 \mathrm{~dB}(\mathrm{~A}) 40 \mathrm{~ms}$ noise burst preceded $10,20,30,60$, or $120 \mathrm{~ms}$ by a prepulse ( $5 \mathrm{~ms}$ noise burst) that was $16 \mathrm{~dB}(\mathrm{~A})$ above background (PP10, PP20, PP30, PP60, and PP120 ms, respectively). The test session was structured identically to that described above for rat 
studies, except that intertrial intervals averaged $20 \mathrm{~s}$ (range 15-25 s).

Reasons for subject disqualification $(n=18$; not included in 'final' sample $n=30$ ) are seen in Table 2 . The primary reasons for disqualification were that subjects had low startle magnitude $(n=6)$ or withdrew from testing prior to the test day $(n=6)$. One subject was not tested because his pretest PPI level (mean PPI $=-30 \%$ ) was $>3$ SD below the rolling group mean. Subjects who passed the 'pretest' screening criteria returned for the test day 7-10 days later, having been instructed to maintain their normal patterns of caffeine consumption prior to testing, based on reported effects of caffeine withdrawal on PPI (Swerdlow et al, 2000a). Subjects were recruited for studies continuously over approximately a 3-month period, and were assigned to active drug $v s$ placebo groups for each drug based on a 'rolling average' strategy, using pretest mean acoustic PPI measures to obtain groups with comparable 'baseline' acoustic PPI values (Swerdlow et al, 2001b).

Our group (Swerdlow et al, 1999) and others (eg Peak 1939; Blumenthal et al, 1996, 2001; Cohen et al, 1981; Perlstein et al, 1993) have reported the ability of prepulses to inhibit the perceived intensity of startling stimuli. A 'LOUDNESS session' was used to test drug effects on this form of 'sensory gating'. During this test, subjects held a pen and sat in front of a music stand that held a stack of paper. On each sheet of paper was a $100 \mathrm{~mm}$ line. Subjects were instructed to make a mark on the line corresponding to their perceived intensity of each noise, with the extreme left end of the line corresponding to 'can't hear', and the extreme right end of the line corresponding to 'intolerably loud'. Subjects were observed remotely to be certain that one piece of paper was used for each startle trial. The LOUDNESS session consisted of 48 trials that included three conditions: P105 (105 dB(A) $40 \mathrm{~ms}$ noise burst), and P105 preceded $120 \mathrm{~ms}$ by either a $12 \mathrm{~dB}$ prepulse (PP12/P105) or a $16 \mathrm{~dB}$ prepulse (PP16/P105), to permit detection of intensity-dependent prepulse effects. This session began with three P105 trials, followed by 15 repetitions of each of the three trial types in pseudorandom order.

On the drug test day, subjects arrived at 0830, received a standardized breakfast and a second urine toxicological examination, and hearing was retested as described in Swerdlow et al (2000a, 2002b). At 0915 subjects consumed either active $(20 \mathrm{mg}$ ) or inactive (placebo) pills; neither subject nor experimenter knew the pill identity. This active dose has previously been reported to disrupt PPI in normal humans (Hutchison and Swift, 1999). Testing started at 0940. The test began and ended with the INTERVAL session (INT1 and INT2). Between these sessions, tests were conducted to assess startle habituation (HAB session) and perceived startle stimulus intensity (LOUDNESS session). The HAB session consisted of 50 repetitions of 40 psi $40 \mathrm{~ms}$ air bursts (PUFF) delivered from a compressed air tank aimed under the subjects' chins via a small rubber tube. A constant intertrial interval of $15 \mathrm{~s}$ was used. The HAB session followed the LOUDNESS session.

Heart rate and blood pressure were determined (sitting position, brachial cuff), and subjects completed a symptom rating scale every $30-45 \mathrm{~min}$, the first one before pill ingestion, the second immediately before the first startle session and thereafter between each startle session and after
Table 2 Reason for Subject Disqualification

\begin{tabular}{lc}
\hline & N \\
\hline Pretest average eyeblink startle magnitude $<50$ & 6 \\
Withdrew prior to test day & 6 \\
SCID-NP: self-reported illicit drug use ${ }^{\text {a }}$ & 3 \\
SCID-NP: major depressive episodes & 1 \\
Hearing impairment & । \\
Pretest PPI $>3$ SD below group & 1 \\
Total & 18
\end{tabular}

aself-reported illicit drug use within past year (MDMA), or past month (marijuana), after denying drug use during phone screen.

bCID-NP (First et al, 1997)

the final session. Symptom rating scales were designed to assess general somatic and psychological symptoms and level of consciousness (modified from Norris, 1971; Bond and Lader, 1974; Bunney et al, 1999), and were identical to those described in Swerdlow et al (2000a, 2002b). Ratings were treated as continuous variables and were analyzed with mixed-design ANOVAs.

For both rat and human studies, PPI was defined as (100-(100 $\times$ magnitude on prepulse trial/magnitude on pulse alone trial)). Startle magnitude and PPI were analyzed with mixed-design ANOVAs, with trial type (and block) as within-subject factors, and drug condition as betweensubject factors. To assess startle habituation in humans, the $\mathrm{HAB}$ session was divided into five blocks of 10 trials each, and startle magnitude was analyzed with block as a withinsubject factor. No consistent drug interactions were noted with eye side (left $v s$ right), and thus the main effects of eye side and interactions are not reported. In humans, ANOVAs were completed using both raw data collected from INT1 and INT2 sessions on the test day, and during the 'pretest' session (for startle measures) or from values recorded prior to drug administration (for autonomic and self-rating measures). Startle data from the INT sessions were analyzed as 'difference scores', using each subject's pretest or predrug performance as a 'baseline'. This approach enhances the sensitivity of the measures, by reducing the impact of between-subject variability on the dependent measures (Swerdlow et al, 2000). Startle, autonomic, and self-rating variables were treated as continuous. For the LOUDNESS session, due to the relatively weak startle pulse $(105 \mathrm{~dB}(\mathrm{~A}))$, several test subjects exhibited minimal or no startle responses to P105 trials; any subject whose mean startle value on these trials was $<10$ units was categorized as a 'nonresponder', and their data was not included in the analysis of \%PPI. Finally, self-ratings for the LOUDNESS session were treated as raw (nontransformed) data, and were also 'range-corrected' as previously described (Swerdlow et al, 1999) so that each value was expressed as a fraction of the range (maximum minus minimum) ratings for that subject. Specific post hoc comparisons were made with one-factor ANOVAs or the Fisher's protected least significant difference test (PLSD); $\alpha$ was 0.05 . In most cases, post hoc comparisons were limited to tests of specific a priori hypotheses (eg that DA agonist effects on PPI would be interval-dependent). For exploratory post hoc comparisons, $\alpha$ was adjusted to reduce the risk of familywise errors. 


\section{RESULTS}

\section{Rat Studies}

Are there interval-dependent effects of amphetamine on PPI in rats?. Amphetamine exhibited dose-dependent reductions in PPI across short- and long-prepulse intervals, in contrast with our previous findings with amantadine (Swerdlow et al, 2001a), or the direct DA agonists pergolide (Swerdlow et al, 2001d), bromocriptine (Swerdlow et al, 2002f), and apomorphine (Swerdlow et al, 2002d). ANOVA revealed a significant effect of dose $(\mathrm{F}=6.86$, df 3,30, $p<0.002)$ and interval $(\mathrm{F}=28.23$, df $4,120, p<0.0001)$, and a significant dose $\times$ interval interaction $(F=5.00$, df $12 / 120$, $p<0.0001$ ). Post hoc comparisons revealed that the $3.0 \mathrm{mg} /$ $\mathrm{kg}$ dose of amphetamine significantly reduced PPI at the $60 \mathrm{~ms}(p<0.0001)$ and $120 \mathrm{~ms}(p<0.0001)$ intervals; this effect missed significance for the $30 \mathrm{~ms}$ interval $(p<0.02)$ using $\alpha$ restricted for multiple comparisons, and was also not significant for either the 10 or $20 \mathrm{~ms}$ intervals (Figure 2a). Examination of the raw startle magnitude on all trial types (Figure $2 \mathrm{~b}$ ) revealed that this effect of amphetamine reflected a true disruption of the startle-inhibiting effects of the prepulses, rather than confounding effects of changes in startle magnitude on pulse alone trials.

\section{Human Studies}

Are there interval-dependent effects of amphetamine on PPI in humans?

Subject characteristics: Relevant characteristics of placebo and amphetamine group subjects are seen in Table 1. Groups did not differ significantly in age, caffeine intake, TPQ or SSS scores, or spontaneous blink rates. The mean amphetamine dose was $0.271 \mathrm{mg} / \mathrm{kg}$. One subject was a selfidentified smoker.

PPI of startle: Compared to baseline (pretest) levels of PPI, there was modest evidence that amphetamine reduced PPI early in the test session (during INT1: 25-40 min postingestion), but not in later testing (LOUDNESS or INT2 sessions: $55-75$ or $150-165$ min postingestion, respectively). Placebo and amphetamine groups exhibited nearly identical levels of PPI during pretesting ( $\mathrm{F}<0.4$; Figure 3 , inset). On the test day, ANOVA revealed a significant effect of prepulse interval $(\mathrm{F}=64.72$, df $4,112, p<0.0001)$, test time (INT1 vs INT2 $)(\mathrm{F}=6.93$, df $1,28, p<0.015)$ and a near-significant interaction of drug $\times$ time $(\mathrm{F}=3.85$, df $1,28, p<0.06)$, and no other significant main or interaction effects. Separate between-group comparisons failed to reveal significant effects of amphetamine on PPI in either INT1 or INT2 tests. However, the drug $\times$ time interaction effect was confirmed by the more sensitive measure of PPI difference scores, which assessed postdrug PPI levels relative to each subject's baseline (pretest) values.

With this more sensitive measure, post hoc comparisons revealed a significant effect of amphetamine on PPI difference scores in the INT1 session (effect of drug: $\mathrm{F}=5.81$, df $1,28, p<0.025$ ) but not the INT2 session (effect of drug: $\mathrm{F}<0.3$ ). In INT1, ANOVA of PPI difference scores revealed no significant effects of prepulse interval or
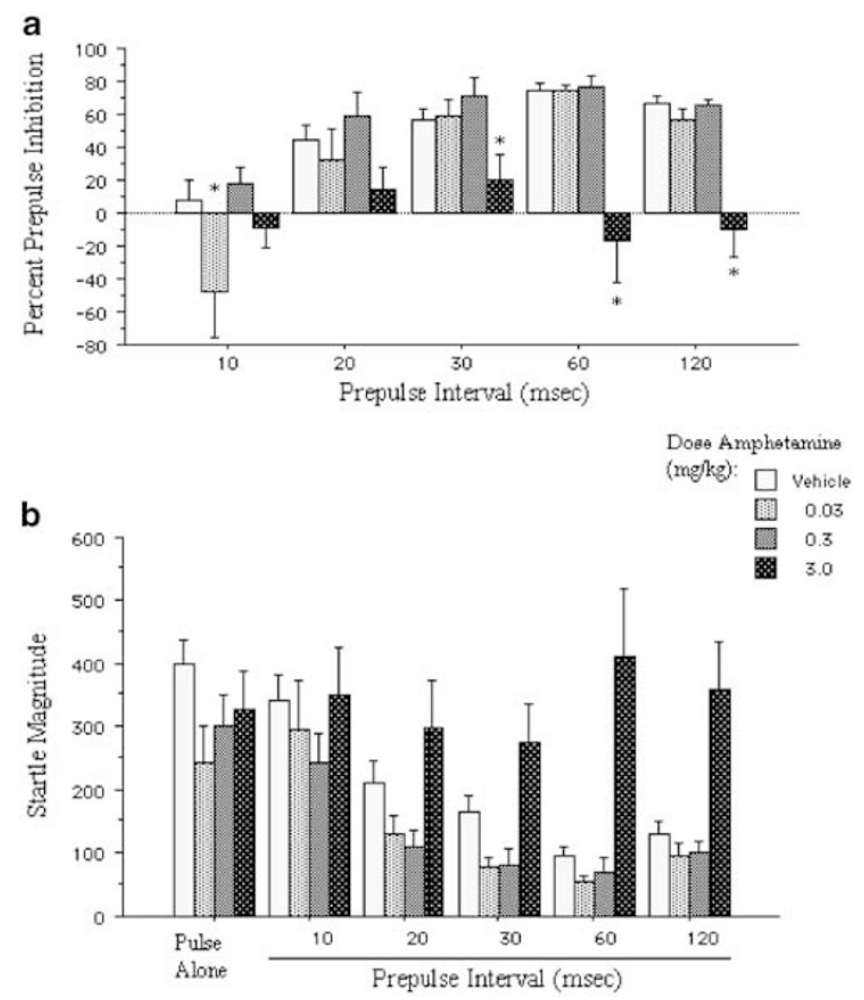

Figure 2 PPI in rats treated with amphetamine. (a) Percent PPI with 10 120 ms prepulse intervals. ANOVA revealed significant prepulse facilitation at $10 \mathrm{~ms}$ prepulse intervals in rats treated with $0.03 \mathrm{mg} / \mathrm{kg}$ amphetamine, and a reduction of PPI at 30 ms prepulse intervals and an elimination of PPI at $60-120 \mathrm{~ms}$ prepulse intervals in rats treated with $3.0 \mathrm{mg} / \mathrm{kg}$ amphetamine (*); by more restrictive criteria $(p<0.01)$, only the effects at $60 \mathrm{~ms}$ $(p<0.000 \mathrm{I})$ and $120 \mathrm{~ms}(p<0.000 \mathrm{I})$ reached statistical significance. (b) Raw startle magnitude from data reduced in Figure 2a, showing clear loss of sensorimotor gating at the highest dose of amphetamine. This dose had no effect on startle magnitude on pulse alone trials, but completely eliminated the startle-inhibiting effects of prepulses at all prepulse intervals.

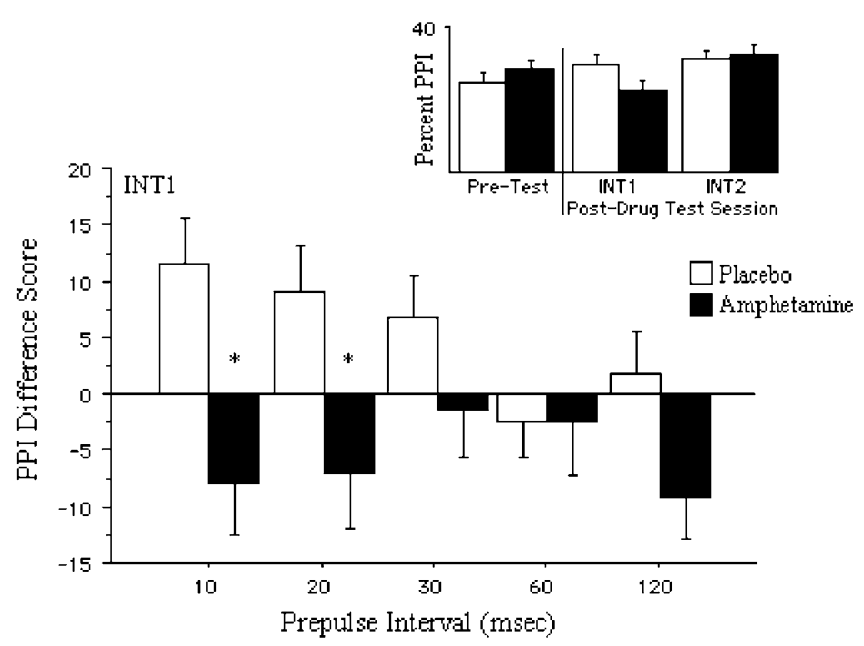

Figure $3 \mathrm{PPI}$ difference scores in placebo and amphetamine group subjects during INTI session. Inset shows mean PPI levels in these groups during pretest (day I), and INTI and INT2 sessions on the test day (day 2). (*) $p<0.05$, placebo vs amphetamine groups at 10 and $20 \mathrm{~ms}$ prepulse intervals. Comparison at $120 \mathrm{~ms}$ intervals yielded only trend values $(p<0.1)$. 
drug $\times$ interval interaction. Inspection of the data (Figure 3) revealed that PPI in placebo group subjects was increased during INT1 compared to their pretest baselines, while PPI in amphetamine group subjects was reduced during INT1, compared to their pretest baselines; both of these effects appeared to be most robust at short prepulse intervals (10$20 \mathrm{~ms}$ ) compared to longer intervals. Since one a priori goal of this study was to assess the amphetamine effect across a range of prepulse intervals, post hoc comparisons at each interval were pursued despite the lack of significant drug $\times$ interval interaction. These revealed significant effects of amphetamine on PPI difference scores at $10 \mathrm{~ms}$ $(p<0.015)$ and $20 \mathrm{~ms}(p<0.04)$ prepulse intervals, but not at 30 or $60 \mathrm{~ms}$ intervals; the effect for $120 \mathrm{~ms}$ intervals only reached trend levels $(p<0.09)$.

No significant effects of amphetamine on PPI were detected in the LOUDNESS session $(\mathrm{F}<0.01$; Figure $4 \mathrm{a})$; all informative interactions were nonsignificant.

Are amphetamine-induced PPI deficits in humans most easily detected in specific subsets of normal subjects, characterized by personality and physiological markers associated with amphetamine sensitivity and brain DA function? Based on previous reports, we assessed the magnitude of the early PPI-reducing effects of amphetamine in subgroups stratified by their characteristics on measures of personality (subscales of the TPQ and SSS), and spontaneous blink rates. To accomplish this, separate ANOVAs of PPI difference scores were performed with subjects divided by median splits of NS scores, SSS scores, and predrug blink rates. While in some cases, amphetamine effects appeared modestly greater in groups characterized by higher or lower median scores, there were no significant interactions between drug group and any of these exploratory grouping factors. Additional statistical strategies using specific TPQ and SSS subscales, or postdrug increases in spontaneous blink rate failed to reveal informative interactions. Specifically, we were not able to reproduce previously reported (Hutchison et al, 1999) significant negative correlations between NS scores and PPI in amphetamine group subjects; in fact, the only statistical trends were towards positive correlations between NS scores and PPI in amphetamine group subjects in INT1 $(R=0.39$, NS $)$ and INT2 $(R=0.48, p<0.075)$, and no relation between NS scores and PPI difference scores $(R=0.07)$. Presented in the manner reported by Hutchison et al (1999), our data appear to exhibit very different patterns (Figure 5a).

The lack of a robust interaction between amphetamine effects and NS scores might have reflected chance differences in baseline PPI among low $v s$ high NS score individuals later assigned to receive placebo $v s$ amphetamine. Analysis of baseline PPI using subsequent drug group assignment and a median split of NS scores revealed no significant effect of drug group $(\mathrm{F}<0.3)$ or interaction between drug group and NS score $(\mathrm{F}<0.9)$. High NS individuals tended to have higher baseline PPI levels, independent of whether they were later assigned to placebo $v s$ amphetamine groups, but this effect reached only trend levels $(\mathrm{F}=3.45$, df $1,26, p<0.075)$. There were no other significant two- or three-way interactions. Thus, it seems unlikely that chance differences in baseline PPI characteristics might have obscured the ability to detect a
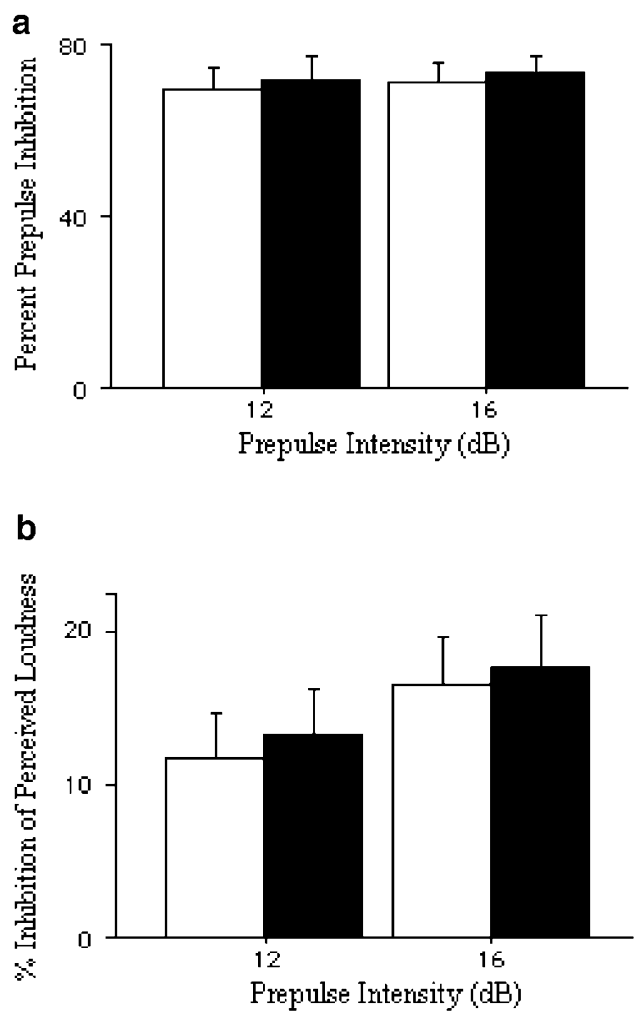

Figure 4 In the LOUDNESS session, neither PPI (a) nor inhibition of perceived pulse loudness (b) differed in amphetamine vs placebo groups.

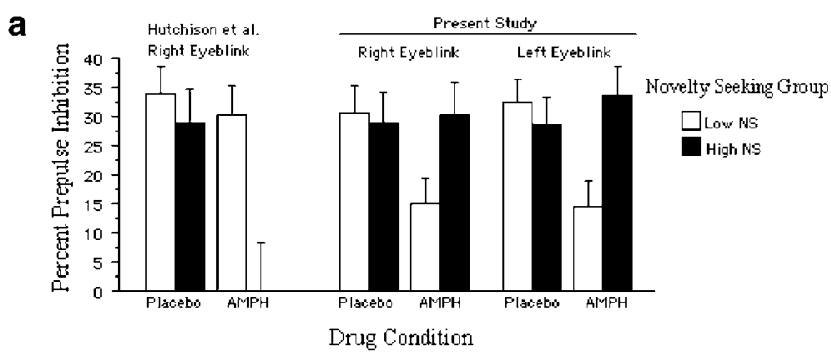

b
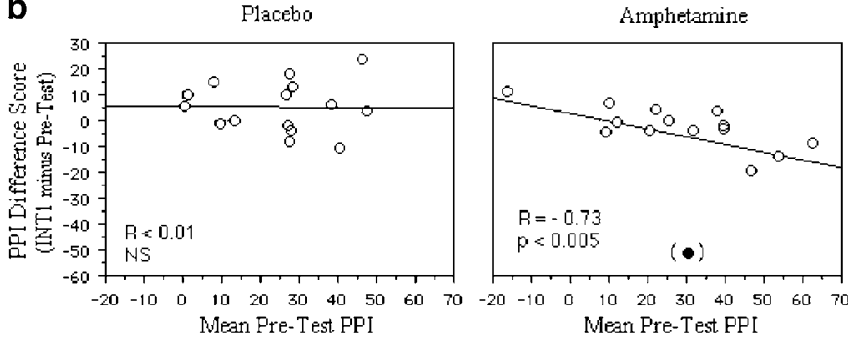

Figure 5 Post hoc analyses of PPI in INTI session. (a) In contrast to Hutchison et al (1999) (data recreated at left of figure), data from the present study did not reveal lower PPI during amphetamine in subjects with high NS scores; in fact, the opposite trend was observed. (b) Amphetamine group subjects with higher pretest PPI values were most sensitive to amphetamine-induced reductions in PPI during the INTI session (right panel), while this relation was not evident in placebo group subjects (left panel). This relation in amphetamine group subjects was statistically significant $(p<0.005)$ only after exclusion of one extreme value

positive relation between NS score and amphetamine sensitivity.

Since our previous findings with amantadine (Swerdlow et al, 2001a) suggested that drug effects on PPI might be 
'range dependent', that is, most robust in individuals whose basal PPI levels were not at 'ceiling' or 'floor' levels, we examined the relation between pretest PPI levels and the effect of amphetamine on PPI difference scores. In placebo group subjects, there was no apparent relation between mean pretest PPI levels and PPI difference scores in INT1 $(R<0.01)$. Interestingly, a simple regression analysis in amphetamine group subjects was suggestive of such a relation (Figure 5b). Although the overall regression $(R=-0.40)$ fell short of statistical significance, analysis of the data after exclusion of a single extreme value (see Figure $5 b)$ resulted in a more convincing pattern $(R=-0.73$, $p<0.005)$. Cautiously, one might interpret these data to suggest that individuals with the highest basal PPI levels were most sensitive to the PPI-reducing effects of amphetamine, but not placebo. Importantly, this relation is not related to the overall 'range' of PPI per se: if this were the case, we would predict that amphetamine effects would be most robust for the longest prepulse intervals, where PPI levels are the highest, while in fact, the opposite was true. Rather, this correlation appears to be based on the pretest PPI characteristics of the test subjects.

Does amphetamine disrupt sensory gating-measured by PPIPSI-and startle reflex habituation in normal human subjects?

Perceived stimulus intensity: Analysis of amphetamine effects on PPIPSI revealed that prepulses reduced perceived startle stimulus intensity overall (effect of trial type: $\mathrm{F}=18.18$, df $2,56, p<0.0001)$, and when analyzed separately in placebo group subjects $(\mathrm{F}=13.29$, df $2,28, p<0.0001)$, and in amphetamine group subjects $(\mathrm{F}=8.67$, df 2,28 , $p<0.002$ ); there was no significant effect of amphetamine on PPIPSI (drug $\times$ trial interaction: $\mathrm{F}=1.01$, df $2,56, \mathrm{NS}$ ). Calculations of range-corrected percent PPIPSI (Figure $4 \mathrm{~b}$ ) revealed approximately $15 \%$ PPIPSI in both placebo and amphetamine groups, averaged over the 12 and $16 \mathrm{~dB}$ prepulses. This value is consistent with our previous reports using this and related paradigms (Swerdlow et al, 1999; 2001a).

Habituation: Robust habituation was seen in both placebo and amphetamine group subjects (Figure 6a; effect of trial block: $\mathrm{F}=19.29$, df 4,112, $p<0.0001$ ), and ANOVA revealed no significant reduction in habituation in amphetamine group subjects ( $\mathrm{drug} \times$ block interaction: $\mathrm{F}=1.15$, df 4,112 , NS).

Autonomic and subjective measures: This provided evidence for 'bioactivity' of the active dose of amphetamine (Figure 6b-d). Compared to placebo group subjects, those receiving amphetamine exhibited increased heart rate, blood pressure, and diminished 'drowsiness'. Some autonomic changes were evident within the first $30 \mathrm{~min}$ of pill ingestion, and all increased across the course of the morning test session. Post hoc assessments failed to reveal any consistent differences in autonomic or subjective effects of amphetamine among subjects stratified by TPQ or SSS characteristics (data not shown), although some autonomic effects of amphetamine appeared to be most robust among individuals with low SSS scores.
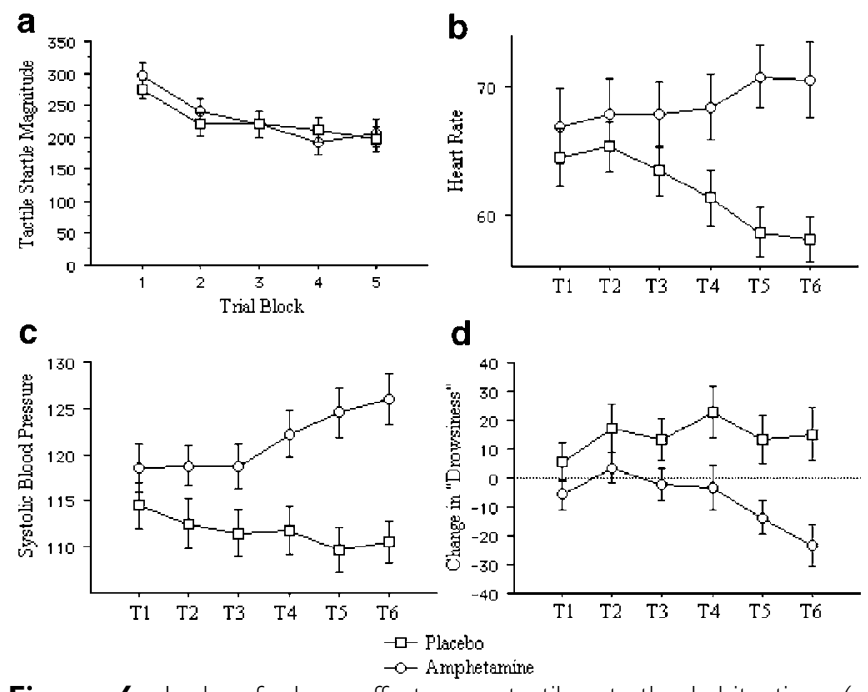

Figure 6 Lack of drug effects on tactile startle habituation (a; comparable reduction in tactile startle magnitude over five trial blocks) but clear evidence of 'bioactivity' of amphetamine, based on measures of heart rate (b; elevated in amphetamine group and reduced in placebo group, across six postpill measurements), 'drowsiness' (c; increased in placebo and reduced in amphetamine group subjects) and systolic blood pressure (d; elevated in amphetamine group and reduced in placebo group).

\section{DISCUSSION}

In the present studies, amphetamine clearly disrupted PPI in rats, but its effects in humans were less convincing. Despite the fact that larger cell sizes were used in humans $(n=15 /$ dose $)$ vs rats $(n=8-10 /$ dose $)$, these effects of amphetamine in humans were evident only when postdrug PPI was compared to each subject's pretest baseline level of PPI. We have discussed the use of this 'pretest' design for PPI drug studies as a means to counter the impact of interindividual differences in a between-subject paradigm, and thereby increase the sensitivity to detect drug effects on PPI (Swerdlow et al, 2001b). Clearly, there is more variability in PPI among a group of normal control humans than there is among a group of genetically identical, agematched rats (eg for $120 \mathrm{~ms}$ PPI, SD (rat, vehicle) =14.94; SD (human, placebo) $=24.43$ ), and the use of PPI difference scores can minimize some of the statistical impact of this human variability. The full within-subject design used by Hutchison and Swift (1999) was even more sensitive to the PPI-disruptive effects of amphetamine, although in that study, amphetamine effects were: (1) also supported by a significant drug $\times$ time interaction when analyzed as a single day, between-subject design, and (2) determined to be the result of a subgroup of subjects characterized by high NS scores.

Tests of our first hypothesis - that the effects of amphetamine on PPI would be interval dependent - yielded mixed results. In rats, amphetamine failed to increase PPI at any interval, unlike effects we have observed previously at short prepulse intervals with direct DA agonists, including pergolide (Swerdlow et al, 2001d), apomorphine (Swerdlow et al, 2002d), and quinpirole (Swerdlow et al, 2002e). The magnitude of the PPI-disruptive effects of the highest dose of amphetamine did appear to be most robust at longer (60- 
$120 \mathrm{~ms})$ vs shorter $(<60 \mathrm{~ms})$ prepulse intervals; in fact, using more restrictive values of $\alpha$ to correct for multiple comparisons, neither the PPI-reducing effects of amphetamine at $10 \mathrm{~ms}$ intervals $(0.03 \mathrm{mg} / \mathrm{kg} ; p<0.025)$ nor $30 \mathrm{~ms}$ intervals $(3.0 \mathrm{mg} / \mathrm{kg}$ amphetamine, $p=0.02)$ would achieve statistical significance. While this effect could not simply be explained by differences in vehicle-group PPI levels at these intervals, the lack of clear shifts in amphetamine dosesensitivity across prepulse intervals suggests that longer latency startle inhibition is not necessarily 'more disruptible' by DA release. At the least we must conclude that, compared to direct DA agonists, we found less evidence that the PPI-disruptive effects of the indirect DA agonist amphetamine in rats undergo a categorical change as the temporal separation between prepulse and pulse increases from 10 to $120 \mathrm{~ms}$.

In humans, PPI difference score analyses did suggest that the effects of amphetamine on PPI were interval-dependent, but the specific pattern of the present results-greatest effects of amphetamine at short (10-20 ms) intervals - could not have been predicted based on preclinical findings. Thus, while the general 'direction' of amphetamine's effects on PPI was similar across species, the temporal features of these effects were quite different.

Certainly, there are many differences between the rat and human experiments that might 'dilute' the degree of crossspecies homology in these studies. Most obviously, startle is measured differently across species: EMG of orbicularis oculi is measured in humans, while a whole-body skeletomotor response is measured in rats. This motor response in humans reflects activation of the seventh cranial nerve, while in rats it reflects widespread activation of spinal motor neurons. Despite these differences in the neuromechanics of startle generation, virtually all hardware and software 'proximal' to the EMG or motion transducer are interchangeable in the human and rat startle systems in the present studies. Importantly, with this equipment, patterns of prepulse modification of startle (rather than startle per se) exhibit striking homology in rats and humans using a range of prepulse intensities and intervals (Swerdlow et al, 1994; 2001a; present study). Differences in drug dose, route of administration and pharmacokinetics, and distribution might clearly lead to different behavioral effects across species. Species differences in PPI variability (human $>$ rat) were discussed above, compounded by logistical difficulties of testing an adequate human sample size to overcome such variability. Less likely to impact cross-species homology were minor differences in the startle sessions (eg mean intertrial intervals of $15 \mathrm{~s}$ (rats) vs $20 \mathrm{~s}$ (humans)) that were designed to accommodate the relatively short-lived effects of subcutaneous amphetamine on PPI in rats (eg Sills, 1999) $v s$ oral amphetamine in humans (Hutchison and Swift, 1999).

Two forms of sensory or sensorimotor gating assessed in this study-PPIPSI and tactile startle habituation - were clearly insensitive to a $20 \mathrm{mg}$ dose of amphetamine. It is difficult to interpret such negative findings, but the lack of amphetamine effect in each case occurred at a time when there was still evidence for amphetamine 'bioactivity'. A divergence between drug effects on PPI $v s$ these two measures was previously observed with amantadine (Swerdlow et al, 2001a), which increased PPI, but disrupted PPIPSI and had no significant effect on startle habituation. Thus, the present study offers at least tentative support for the notion that these three measures of reduced impact of an intense startling stimulus are differentially regulated by brain DA systems.

Both the present study and that of Hutchison and Swift (1999) identify subtle but significant PPI-disruptive effects of $20 \mathrm{mg}$ oral amphetamine in normal human subjects. In both studies, 'bioactivity' of amphetamine was confirmed via autonomic and subjective measures. However, there were some notable differences in the findings in these two studies. Hutchison and Swift (1999) detected the PPIreducing effects of amphetamine $90 \mathrm{~min}$ postingestion, but not 60 or $120 \mathrm{~min}$ postingestion. In the present study, we observed these effects 25-40 min postingestion, but not 5575 or $150-165 \mathrm{~min}$ postingestion. And unlike Hutchison et al (1999), we failed to observe any significant relations between amphetamine effects on PPI and personality markers associated with brain DA function - and thus failed to find support for our second hypothesis. In fact, one important pattern observed by Hutchison et al (negative correlation between NS scores and PPI after amphetamine: $R=-0.47$ ) was almost precisely arithmetically opposite to that observed in the present study (positive correlation between NS scores and PPI after amphetamine: $R=+0.48$ ). Without a direct analysis (eg Fisher's $\mathrm{r}$ to $\mathrm{Z}$ transformation (Hays, 1966)), it is impossible to determine whether these correlations are significantly different from each other, but at least it would be safe to conclude that we were unable to replicate this earlier significant negative correlation. PPI

Table 3 Similarities and Differences between the Present Study and Hutchison et al (1999)

\begin{tabular}{lll}
\hline & \multicolumn{1}{c}{ Present study } & \multicolumn{1}{c}{ Hutchison et al (1999) } \\
\hline Subjects & Male $(n=30)$ & Male and female $(n=30)$ \\
NS score (median) & 19 & 19 \\
Dose amph (mg p.o.) & 20 & 20 \\
Design & Pre- vs postdrug between subject & Cross-over within subject and pretest baseline session \\
Eyeblink side & Bilateral & Right \\
Background noise (dB(A)) & 65 & 54 \\
Prepulse type & White noise (5 ms) & $800 \mathrm{~Hz}$ tone (30 ms) \\
Prepulse intensity (dB over background) & $12-16$ & 4 \\
Prepulse interval (ms) & $10-120$ & 120 \\
Pulse intensity (dB over background) & $40-53$ & 51 \\
Pulse duration (ms) & 40 & 50 \\
Measurement times (min after ingestion) & $25-40,55-75,150-165$ & (Start time) 60, 90, 120 \\
\hline
\end{tabular}


levels during amphetamine ingestion are likely a reflection of both 'baseline' PPI characteristics (ie 'trait' features) and amphetamine effects on PPI (ie 'state' features), so one must consider the possibility that these two studies differ in the 'trait' characteristics of the subjects; importantly, the populations tested in the two studies had identical median NS scores (Table 3 ).

Many differences in experimental design could account for the somewhat (though not entirely) discrepant findings between the present report and that of Hutchison et al (1999). First, their study included both male and female subjects, while ours included only males. Although Hutchison and Swift (1999) reported no significant interactions with gender that could account for their significant amphetamine $\times$ time interaction, it is conceivable that even 'nonsignificant' gender differences might have contributed to the different overall statistical impact of NS scores on amphetamine effects in the two studies. Second, Hutchison and Swift (1999) recorded right eyeblink PPI, while the present study recorded bilateral measures; however, separate inspection of right eyeblink measures from our present study revealed patterns that were essentially indistinguishable from our combined bilateral measures (Figure 5a). Third, substantial differences in stimulus characteristics and response ranges (Table 3 ), and other design features (eg use of a 'baseline' pretest on the day of drug testing (Hutchison and Swift 1999) vs 1 week prior to drug testing (present study)) might also have contributed to the small discrepancies. That subtle differences in stimulus characteristics or design features might result in different effects of amphetamine on PPI might seem far-fetched, but is supported by the fact that we previously failed to observe PPI-disruptive effects of amphetamine in a small group of subjects (Swerdlow et al, 2002b) using a startle session that included only $100 \mathrm{~ms}$ prepulse intervals, and a test day that was similar in many ways to the one used in the present study. Based on our present findings (Figure 3), it is likely that a test session that included only $100 \mathrm{~ms}$ prepulse intervals would also have failed to detect amphetamine effects on PPI in the current study.

Some disparity in the outcomes of these studies across sites is not unexpected; even among the numerous published reports of amphetamine effects on PPI in rats - where there is striking consistency in the general outcome (amphetamine disrupts PPI) - there are also some inconsistencies in the magnitude, dose, and stimulus sensitivity of this effect across studies (cf Geyer et al, 2001). An optimistic perspective is that, despite substantial differences in experimental design, both the present study and that of Hutchison and Swift (1999) detected significant, albeit weak PPI disruptive effects of a DA agonist, that might ultimately be suitable for pharmacologic and other mechanistic studies that will shed light on the biology of sensorimotor gating in humans. However, a difficult hurdle in this process is the limited range of drug doses that are suitable for human experiments. Consistent with previous reports (Mansbach et al, 1988; Martinez et al, 1999), our present data confirm that in rats, the PPI-disruptive effects of indirect DA agonists are relatively weak, occurring most reliably at doses greater than $1 \mathrm{mg} / \mathrm{kg}$ amphetamine. While we cannot make direct comparisons of drug doses across species, it is evident that comparable oral doses of amphetamine in drug-naive humans are not ethical. One 'compromise' strategy for the cross-species translation of PPI neurochemistry would involve infrahuman primates; for example, there is promising evidence for homology in the NMDA regulation of PPI between rodents and adult monkeys (Cebus apella) (Linn and Javitt, 2001). Other reasonable strategies for maximizing the utility of the human amphetamine/PPI paradigm might include: (1) experimental manipulations that increase the sensitivity of PPI to the effects of the present, relatively low doses of amphetamine (eg limiting studies to individuals with relatively high basal levels of PPI, whom in the present study appeared to be most sensitive to the PPI-disruptive effects of amphetamine); (2) use of higher doses of amphetamine via titration over many days or weeks of oral administration, similar to doses achieved in the treatment of clinical conditions such as attention deficit hyperactivity disorder; or (3) use of alternative routes of drug administration (eg intravenous) or subject populations (eg stimulant abusers). As we pursue this work, together with studies of other DA agonists, we are aware that some of these strategies may limit the feasibility or 'generalizability' of this paradigm and its predictive and construct validity for PPI deficits in specific neuropsychiatric disorders.

\section{ACKNOWLEDGEMENTS}

Studies were supported by MH59803 and MH01436. The authors also acknowledge Dr Kristin Cadenhead for providing medical coverage for test subjects, Dr Mark Geyer for formative discussions, and Dr Kent Hutchison for his generosity in providing a 'prereview' of this manuscript.

\section{REFERENCES}

Abduljawad KAJ, Langley RW, Bradshaw CM, Szabadi E (1997). Evidence for involvement of D2 dopamine receptors in prepulse inhibition of the startle reflex in man. Psychopharmacology 11: 69.

Abduljawad KA, Langley RW, Bradshaw CM, Szabadi E (1998). Effects of bromocriptine and haloperidol on prepulse inhibition of the acoustic startle response in man. Psychopharmacology 12: 239-245.

Blumenthal TD, Burnett TT, Swerdlow CD (2001). Prepulses reduce the pain of cutaneous electrical shocks. Psychosom Med 63: $275-281$.

Blumenthal TD, Schicatano EJ, Chapman JG, Norris CM, Ergenzinger Jr ER (1996). Prepulse effects on magnitude estimation of startle-eliciting stimuli and startle responses. Percept Psychophys 58: 73-80.

Bond AJ, Lader MH (1974). The use of analogue scales in rating subjective feelings. Br J Med Psychol 47: 211-218.

Braff DL, Freedman R (2002). Endophenotypes in studies of the genetics of schizophrenia. In: Davis KL, Charney D, Coyle JT, Nemeroff C (eds.), ACNP 5th Generation of Progress, Lippincott Williams and Wilkins: Philadelphia, PA, pp 703-716.

Bunney Jr WE, Hetrick WP, Bunney BG, Patterson JV, Jin Y, Potkin SG et al (1999). Structured interview for assessing perceptual anomalies (SIAPA). Schizophr Bull 25: 577-952.

Carter RJ, Lione LA, Humby T et al (1999). Characterization of progressive motor deficits in mice transgenic for the human Huntington's disease mutation. J Neurosci 19: 3248-3257. 
Cloninger CR, Przybeck TR, Svrakic DM (1991). The tridimensional personality questionnaire: US normative data. Psychol Rep 69: 1047-1057.

Cohen ME, Hoffman HS, Stitt CL (1981). Sensory magnitude estimation in the context of reflex modification. J Exp Psychol: Hum Percept Perform 7: 1363-1370.

Curzon P, Kim DJ, Decker MW (1994). Effects of nicotine, lobeline, and mecamylamine on sensory gating in the rat. Pharmacol Biochem Behav 49: 877-882.

Duncan EJ, Madonick SH, Parwani A, Angrist B, Rajan R, Chakravorty $S$ et al (2001). Clinical and sensorimotor gating effects of ketamine in normals. Neuropsychopharmacology 25: $72-83$.

First MB, Spitzer RL, Gibbon M, Williams JBW (1997). Structured clinical interview for DSM-IV axis I disorders, research version, non-patient edition (SCID-I/NP). Biometrics Research, New York State Psychiatric Institute: New York.

Geyer MA, Braff DL (1982). Habituation of the blink reflex in normals and schizophrenic patients. Psychophysiology 19: 1-6.

Geyer MA, Krebs-Thomson K, Braff DL, Swerdlow NR (2001). Pharmacological studies of prepulse inhibition models of sensorimotor gating deficits in schizophrenia: a decade in review. Psychopharmacology 156: 117-154.

Hays WL (1966). Statistics for psychologists. Holt, Rinehart \& Winston: New York, NY.

Hazlett EA, Buchsbaum MS, Haznedar MM, Singer MB, Germans MK, Schnur DB et al (1998). Prefrontal cortex glucose metabolism and startle eyeblink modification abnormalities in unmedicated schizophrenia patients. Psychophysiology 35: 186198.

Hutchison KE, Swift R (1999). Effect of D-amphetamine on prepulse inhibition of the startle reflex in humans. Psychopharmacology 143: 394-400.

Hutchison KE, Wood MD, Swift R (1999). Personality factors moderate subjective and psychophysiological responses to $d$-amphetamine in humans. Exp Clin Psychopharmacol 7: 493-501.

Joober R, Zarate JM, Rouleau GA, Skamene E, Boksa P (2002). Provisional mapping of quantitative trait loci modulating the acoustic startle response and prepulse inhibition of acoustic startle. Neuropsychopharmacology, 27: 765-781.

Karson CN, Burns RS, LeWitt PA, Foster NL, Newman RP (1984). Blink rates and disorders of movement. Neurology 34: 677-678.

Karson CN, Staub RA, Kleinman JE, Wyatt RJ (1980). Drug effect on blink rates in Rhesus monkeys: preliminary studies. Biol Psychiatry 16: 249-255.

Kodsi MH, Swerdlow NR (1997). Mitochondrial toxin 3-nitropropionic acid produces startle reflex abnormalities and striatal damage in rats that model some features of Huntington's disease. Neurosci Lett 231: 1-5.

Kumari V, Checkley SA, Gray JA (1996). Effect of cigarette smoking on prepulse inhibition of the acoustic startle reflex in healthy male smokers. Psychopharmacology 128: 54-60.

Kumari V, Mulligan OF, Cotter PA et al (1998). Effects of single oral administrations of haloperidol and $d$-amphetamine on prepulse inhibition of the acoustic startle reflex in healthy male volunteers. Behav Pharmacol 9: 567-576.

Linn GS, Javitt DC (2001). Phencyclidine (PCP)-induced deficits of prepulse inhibition in monkeys. Neuroreport 12: 117-20.

Mansbach RS, Braff DL, Geyer MA (1989). Prepulse inhibition of the acoustic startle response is disrupted by $N$-ethyl-3,4methylenedioxy-amphetamine (MDEA) in the rat. Eur $J$ Pharmacol 167: 49-55.

Mansbach RS, Brooks EW, Sanner MA, Zorn SH (1998). Selective dopamine D4 receptor antagonists reverse apomorphine-induced blockade of prepulse inhibition. Psychopharmacology 135: 194-200.
Mansbach RS, Geyer MA (1989). Effects of phencyclidine and phencyclidine biologs on sensorimotor gating in the rat. Neuropsychopharmacology 2: 299-308.

Mansbach RS, Geyer MA, Braff DL (1988). Dopaminergic stimulation disrupts sensorimotor gating in the rat. Psychopharmacology 94: 507-514.

Martinez ZA, Ellison GD, Geyer MA, Swerdlow NR (1999). Effects of sustained cocaine exposure on sensorimotor gating of startle in rats. Psychopharmacology 142: 253-260.

Martinez ZA, Platten A, Pollack E, Shoemaker J, Ro H, Pitcher L et al (2002). 'Typical' but not 'atypical' antipsychotic effects on startle gating deficits in prepubertal rats. Psychopharmacology, 161: 38-46.

Martin-Iverson MT, Else D (2000). PHNO, a selective D2 receptor agonist, does not reduce prepulse inhibition of the startle reflex in rats. Psychopharmacology 151: 38-48.

Norris H (1971). The action of sedation on brain-stem oculomotor systems in man. Neuropharmacology 10: 181-191.

Peak H (1939). Time order error in successive judgements and in reflexes. I. Inhibition of the judgement and the reflex. $J$ Exp Psychol 25: 535-565.

Perlstein WM, Fiorito E, Simons RF, Graham FK (1993). Lead stimulation effects on reflex blink, exogenous brain potentials, and loudness judgments. Psychophysiology 30: 347-358.

Sills TL (1999). Amphetamine dose dependently disrupts prepulse inhibition of the acoustic startle response in rats within a narrow time window. Brain Res Bull 48: 445-448.

Swerdlow NR, Braff DL, Taaid N, Geyer MA (1994). Assessing the validity of an animal model of deficient sesorimotor gating in schizophrenic patients. Arch Gen Psychiatry 51: 139-154.

Swerdlow NR, Casas R, Bruins P, Wasserman L, Talledo J, Stephany NL (2002a). Prestimulus modification of the startle reflex: relationship to personality and physiological markers of dopamine function. Biol Psychiatry 51: 174S.

Swerdlow NR, Eastvold A, Gerbranda T, Uyan KM, Hartman P, Doan Q (2000a). Effects of caffeine on sensorimotor gating of the startle reflex in normal control subjects: impact of caffeine intake and withdrawal. Psychopharmacology 151: 368-378.

Swerdlow NR, Eastvold A, Karban B, Ploum Y, Stephany N, Geyer MA et al (2002b). Dopamine agonist effects on startle and sensorimotor gating in normal male subjects: time course studies. Psychopharmacology 161: 189-201.

Swerdlow NR, Eastvold A, Ross L, Karban B, Ralledo J, Stephany N et al (2001a). Effects of amantadine on startle gating in normal male humans and rats. Abstr Soc Neurosci 27: 540.17.

Swerdlow NR, Eastvold A, Uyan KM, Ploum Y, Cadenhead K (2001b). Matching strategies for drug studies of prepulse inhibition in humans. Behav Pharmacol 12: 45-52.

Swerdlow NR, Geyer MA (1998). Using an animal model of deficient sensorimotor gating to study the pathophysiology and new treatments of schizophrenia. Schizophr Bull 24: 285-302.

Swerdlow NR, Geyer MA, Blumenthal TD, Hartman PL (1999). Effects of discrete acoustic prestimuli on perceived magnitude and behavioral responses to startling acoustic and tactile stimuli. Psychobiology 27: 453-461.

Swerdlow NR, Martinez ZA, Hanlon FM, Platten A, Farid M, Auerbach $\mathrm{P}$ et al (2000b). Towards understanding the biology of a complex phenotype: rat strain and substrain differences in the sensorimotor gating-disruptive effects of dopamine agonists. $J$ Neurosci 20: 4325-4336.

Swerdlow NR, Paulsen J, Braff DL, Butters N, Geyer MA, Swenson MR (1995). Impaired prepulse inhibition of acoustic and tactile startle in patients with Huntington's disease. J Neurol Neurosurg Psychiatry 58: 192-200.

Swerdlow NR, Pitcher L, Noh HR, Auerbach P, Shoemaker JM (2002c). Startle gating in rats is disrupted by chemical inactivation but not D2 stimulation of the dorsomedial thalamus. Biol Psychiatry 51: 63S. 
Swerdlow NR, Platten A, Kim YK, Gaudet I, Shoemaker J, Pitcher L et al (2001c). Sensitivity to the dopaminergic regulation of prepulse inhibition in rats: evidence for genetic, but not environmental determinants. Pharmacol Biochem Behav 70: 219-226.

Swerdlow NR, Platten A, Shoemaker J, Pitcher L, Auerbach P (2001d). Effects of pergolide on sensorimotor gating of the startle reflex in rats. Psychopharmacology 158: 230-240.

Swerdlow NR, Shoemaker JM, Pitcher L, Goins J, Platten A (2002e). Temporal profile of startle gating reveals a D2 substrate for genetic differences in apomorphine sensitivity in outbred rats. Abstr Soc Neurosci, 782.3.

Swerdlow NR, Shoemaker JM, Pitcher L, Platten A, Kuczenski R, Eleey CC et al (2002d). Genetic differences in startle gatingdisruptive effects of apomorphine: evidence for central mediation. Behav Neurosci, 116: 682-690.

Swerdlow NR, Shoemaker JM, Wasserman L, Talledo J, Stephany NL (2002f). Bromocriptine effects on prepulse inhibition (PPI)

and other gating measures across species. Biol Psychiatry 51: 27S.

Swerdlow NR, Taaid N, Oostwegel JL, Randolph E, Geyer MA (1998). Towards a cross-species pharmacology of sensorimotor gating: effects of amantadine, bromocriptine, pergolide and ropinirole on prepulse inhibition of acoustic startle in rats. Behav Pharmacol 9: 389-396.

van Berckel BN, Oranje B, van Ree JM, Verbaten MN, Kahn RS (1998). The effects of low dose ketamine on sensory gating, neuroendocrine secretion and behavior in healthy human subjects. Psychopharmacology 137: 271-281.

Vollenweider FX, Remensberger S, Hell D, Geyer MA (1999). Opposite effects of 3,4-methylenedioxy-methamphetamine (MDMA) on sensorimotor gating in rats versus healthy humans. Psychopharmacology 143: 365-372.

Zuckerman M, Bone RN, Neary R, Mangelsdorf D, Brustman B (1972). What is the sensation seeker? Personality trait and experience correlates of the sensation seeking scales. J Consult Clin Psychol 39: 308-321. 